\title{
Pesantren Aceh sebagai Wujud Menciptakan Perdamaian
}

\author{
${ }^{1}$ Aida Hayani, ${ }^{2}$ Miftahus Sa'diyah, ${ }^{3}$ Khairul Hadi \\ ${ }^{1}$ Jurusan Tarbiyah UIN Sunan Kalijaga, Yogyakarta, Indonesia \\ ${ }^{2}$ Jurusan Tarbiyah IAIN Jember, Indonesia \\ ${ }^{3}$ Fakultas Syariah IAIN Jember, Indonesia
}

\begin{abstract}
According to the majority religious groups, in truth, always give priority boarding to the authority ta'dzim culture and a religious teacher Tgk, the more their binding normative frame, such as the doctrine of al-Muta'alim Ta'lim book, which does not allow the conflict in it. However, that happens, the social dynamics of schools that still apply the system of management of the potential sources based on a figure of clerics (as a role model at the same time policy makers), is actually very vulnerable to grow a conflict. As is the case in traditional Islamic boarding schools and semi-modern, conflicts occur, especially when the clerics who plays as the founder and owner of boarding dies, or when the pesantren, the founder or the resume, the teachers, caregivers, or also the family become involved in affairs outside of schools, for example, state, politics and others. By using descriptive analysis method with dispute resolution theory, This research uses a qualitative approach with the type of phenomenological study through field studies. then, the formulation of problem is: How is conflict resolution in boarding using unique methods? The results show that including through intermarriage boarding, istighotsah, haul and akhirussanah. By stage of conflict resolution through the streets silaturrahmi as a process of conflict prevention, bahtsul matsa'il as the emphasis and conflict insulation, Tabayun as the process of setting and managing conflict and reconciliation as the final process of conflict resolution.
\end{abstract}

Keywords: Boarding school, Resolution, Aceh

\section{Pendahuluan}

Pesantren dipahami sebagai tempat yang sejuk tenang dan damai. Di dalamnya terdapat cantrik (santri) yang mencurahkan tenaga dan pikirannya untuk belajar membentuk karakter, sementara, sang Tgk menyerahkan diri dan jiwa mereka dengan tulus untuk memberikan pengajaran dan tauladan hidup (Hairus salim dalam Hamdan Farchan Syarifudin, 2004,). Solidaritas, kebersamaan, persaudaraan dan ketulusan antarwarga sungguh sangat kuat dan tumbuh sebagai karakter integral dari kehidupan pesantren. Berbeda dengan definisi di atas, Nur Cholis Madjid (2009b) mengulas tentang pesantren itu sebagai bagian dari sistem pendidikan di Indonesia. Menurutnya, dari segi historis pesantren tidak identik dengan makna keislamian, akan tetapi, juga mengandung makna keaslian Indonesia (indigenous). Mengingat, sejatinya, lembaga yang serupa dengan pesantren sudah ada pada masa kekuasaan Hindu-Budha, sehingga, Islam tinggal meneruskan dan mengislamkan lembaga pendidikan yang sebelumnya sudah ada. Bagi orang yang mengenal akrab tradisi pesantren atau yang selama ini hidup terbiasa di lingkungan pesantren, serta yang pernah menjadi santri atau memang terlahir dan besar di keluarga pesantren, maka,akan sangat 
terkejut, ketika ada yang menguak terjadinya suatu pertengkaran, konflik, permasalahan bahkan sampai menjadi suatu resolusi konflik di dalam lembaga pendidikan tersebut. Menurut mayoritas kelompok santri, pesantren selalu mengedepankan kebudayaan ta'dzim kepada wibawa seorang ustadz dan Tgk, lebih-lebih adanya bingkai normatif yang mengikat sebagaimana ajaran pada kitab Ta'lim al-Muta'alim (Kitab Kuning yang isinya mengajarkan sopan santun dan andap ashor, tata krama antara murid dan guru. Biasanya dipakai pedoman pada pesantren secara umum, baik di pesantren salaf maupun modern), sehingga tidak memungkinkan terjadi mengembangkan paham tawasuth (tidak memihak), tawazun (menjaga keseimbangan dan keharmonisan), tasamuh (toleransi). (keadilan) dan tasyawur (musyawarah) seperti yang di himpun dalam Ushul Al Khamsah..Oleh sebab itu, di dalam suatu bingkai tradisi yang sedemikian rupa, maka, sungguh sangat mustahil benih-benih konflik bisa berkembang di pesantren. Menurut mereka, konflik apapun yang terjadi di suatu pesantren selalu bisa diselesaikan dengan baik lewat kharisma seorang Tgk atau kewalian seorang pewaris nabi (tradisi yang dikembangkan).

Dengan kata lain, ketika Tgk dawuh atau dalam skala yang lebih besar memberikan tawsiyah pada semua pihak, maka, semua urusan pun langsung selesai. Akan tetapi, yang terjadi, dinamika sosial pesantren yang masih menerapkan sistem manajemen pengelolaan sumber-sumber potensi berdasarkan figur seorang Tgk (sebagai suatu panutan sekaligus pengambil kebijakan), sangat rentan bagi tumbuhkembangnya sebuah konflik di dalam lembaga pendidikan tersebut. Hal itu selaras dengan yang banyak terjadi di pesantrenpesantren tradisional dan semimodern. Konflik terjadi, utamanya ketika sang Tgk yang berposisi sebagai pendiri sekaligus pemilik pesantren tersebut meninggal dunia, atau ketika Tgk pesantren, pendiri atau yang melanjutkan, para ustadz, pengasuh, dan juga para keluarga ikut melibatkan diri pada urusan di luar pesantren, misalnya kenegaraan, politik dan lain lain (Hamdan Farchan Syarifudin, 2004). Dalam situasi demikian, suasana pesantren yang mulanya sarat dengan harmoni, kebersamaan, persaudaraan, dan ketulusan antarwarga biasanya ikut berubah akibat sikap dan pilihan hidup kalangan elitnya. Sejatinya, banyak contoh-contoh yang terjadi, hanya saja, kasuskasus tersebut jarang terungkap. Mengingat, bagi kalangan pesantren, membeberkan apa yang sesungguhnya terjadi di pesantren (khusus yang negatif) adalah suatu hal yang tabu. Terlebih lagi yang menyangkut dapur keluarga pesantren, karena bisa mendatangkan tulah. Kenyataan yang tersebut di atas, berkebalikan dengan apa yang dibayangkan banyak orang tentang pesantren yang adem ayem, jauh dari keingaran urusan duniawi. Menurut mereka pondok tempat orang menempa derajat spiritual keagamaan yang terbebas dari suasana konflik kepentingan dalam hal apapun, ternyata memendam suatu permasalahan yang sewaktuwaktu dapat menimbulkan dampak baik atau buruk bagi lembaga maupun orang yang tergabung di dalamnya. Terlebih ketika para elit terlibat dengan pelbagai urusan di luar pesantren.

\section{Konflik dalam dunia pesantren}

Konflik dalam kehidupan bisa diasumsikan sebagai relitas, konflik bisa terjadi antara individu dengan individu dengan komunitas masyarakat, atau antarkomunitas masyarakat. Konflik bisa terjadi di mana saja, kapan saja, oleh siapa saja. Konflik bersifat vertikal bila terjadi 
antar sesama elit masyarakat, vertikalhorizontal, elit masyarakat versus masyarakat, maupun horizontal yakni benturan antar sesama masyarakat (Hamdan Farchan Syarifudin, 2004). Tidak ada yang bisa menepis, di dunia pesantren, konflik adalah merupakan hal yang nyata. Namun bagi masyarakat pesantren, kenyataan tersebut dipahami sebagai hal yang tidak perlu diungkap dan dibesar-besarkan. Kecenderungan untuk tidak merespon konflik disebabkan bahwa perbedaan adalah merupakan realitas hidup dan pasti ada hikmah di balik itu --- hal ini merupakan suatu kesadaran bahwa perbedaan sebagai realitas bersumber dari norma agama.

Dengan demikian, secara teologis, pemaknaan perbedaan dipahami sebagai sunnatullah dan harus bersifat konstruktif yang membawa kepada kebajikan. Selain karena landasan tersebut, faktor kultural juga menentukan dalam menyikapi konflik. Bagi masyarakat pesantren, mengungkap dan membesar-besarkan masalah adalah merupakan hal yang tabu --- hal tersebut selaras betapa konflik yang mencuat dari suatu institusi agama dapat menimbulkan aib dan pada gilirannya melahirkan sikap "diam itu emas" daripada memperbincangkan konflik yang terjadi. Dengan kata lain, nilai agama dan norma kultur yang tersebut di atas menciptakan suatu model dalam mengatasi konflik ala pesantren. Oleh sebab itu, bila terjadi perbedaan yang rentan terhadap konflik bahkan manifes, biasanya, dunia pesantren mengatasinya dengan kultur yang diyakini masyarakat mempunyai kemampuan dan kapasitas dalam mengatasinya lewat peranan Tgk sebagai individu yang diyakini merupakan elit tradisional dalam dunia pesantren.

Dalam hal ini, elit adalah merupakan aktor yang mempunyai kekuasaan, sehingga dapat dikatakan sebagai orang atau kelompok yang memegang posisi terkemuka dalam masyarakat (Suzane Keller, 1995). Sementara, Abdurrahman Wahid (1988) berpendapat peran Tgk sebagai agen budaya bukan berarti Tgk sebagai makelar budaya (cultur broker). Sebagai agen budaya karena Tgk memiliki peran ganda, di satu sisi sebagai pengasuh, pemilik pesantren, pembimbing santri, pengayom umat, sedang di sisi lain ia sebagai asimilasi kebudayaan luar yang masuk ke pesantren. Dalam hal ini, Abdurrahman Wahid (dalam Greg Fealy dan Greg Barton, 1997) menyitir pendapat Hiroko Horikoshi bahwa peran sosial Tgk menunjukkan betapa daya dorong dan perubahan itu datang dari pemikiran agama yang diiringi interaksi panjang dengan modernisasi. Oleh sebab itu, banyak pesantren yang oleh pendirinya semula merupakan satu kesatuan instansi, dalam perjalanannya terbelah menjadi dua atau bahkan lebih. Pemisahan tersebut terjadi akibat adanya konflik di dunia pesantren yang timbul lantaran interes pribadi, kemudian menjadi konflik permanen dan berimbas pada konflik antar pesantren.

\section{Konflik Dunia Pesantren dan pandangan masyarakat Aceh}

Dunia pesantren memandang konflik sebagai hal yang biasa, pendapat ini bersumber dari pemahaman normatif tentang diakuinya perbedaan dan diyakini sebagai suatu kewajaran yang biasa membawa rahmat. Namun demikian, masyarakat pesantren tidak menghendaki adanya konflik dan selalu berharap agar setiap konflik dapat segera terselesaikan. Secara umum, tidak seorangpun Tgk menghendaki bila konflik tersebut membawa mudharat bagi orang lain. Konflik sengaja dan segara dilokalisir agar tidak membias dan tidak melibatkan 
orang banyak. Bahkan cenderung disederhanakan agar tidak dijadikan komoditas oleh pihak-pihak tertentu yang ingin mengambil keuntungan.

Namun tidak dapat dipungkiri, ada pula Tgk yang memperlakukan konflik sebagai komoditas untuk mendapatkan keuntungan materiil maupun popularitas. Kemungkinan konflik bisa membawa mudhorot, sungguh sangat disadari oleh pesantren. Sehingga, bila konflik muncul, maka, ada keinginan yang kuat untuk segera menyelesaikannya atau andaikan konflik tersebut menjurus ke manifes sesegera mungkin dapat dilokalisir dan disederhanakan agar tidak menjadi bahan komoditas. Kekhawatiran bahwa konflik bisa dimanfaatkan oleh pihak tertentu diakui oleh ulama dan tgk di Aceh. Walau begitu, mayoritas Tgk pesantren mengaku tidak punya kepentingan terhadap konflik yang terjadi. Namun tidak semua konflik bersumber dari internal, faktor-faktor eksternal juga berpengaruh besar atas peristiwa konflik yang terjadi di pesantren. Sikap Tgk dalam menyikapi konflik yang disebabkan oleh faktor eksternal terbilang unik, Tgk tampak resisten atau jika situasi politik menuntut, antar Tgk seolah berkonflik. Seperti biasa, menjelang kampaye, masing-masing pihak menyusun isu untuk menyerang partai lawannya. Sudah barang tentu, dampak perseteruan itu berimbas pada institusi pesantren yang dipimpin oleh keduanya lantaran figur ulama dan Tgk menjadi panutan bagi para santrinya. Secara teologis, masyarakat pesantren tidak memahami konflik dalam makna destruktif, mengingat perbedaan adalah merupakan rahmat Allah. Pemahaman tersebut menumbuhkan kesadaran pluralisme dan pemikir yang terbuka. Masyarakat pesantren menyangkal bahwa konflik yang terjadi di dunia pesantren sama dengan konflik sosial yang terjadi di masyarakat umum. Menurut mereka, konflik yang terjadi hanya sebatas bentuk perbedaan yang masih dapat ditolerir dalam norma pesantren. Pesantren tidak boleh dilibatkan bila terjadi perbedaan antar individu karena pada dasarnya perbedaan itu suatu realitas. Perbedaan adalah rahmat. Artinya, bila ada konflik antar individu Tgk jangan sampai berimplikasi terhadap institusi pesantren, sebab bila hal itu terjadi, maka, akan jadi laten dan bersifat institusional antar pesantren. Selaras dengan yang tersebut di atas, sejatinya, ada hal yang selama ini dijadikan pedoman masyarakat pesantren dalam menyikapi konflik, yakni tidak mau mengungkapkan konflik yang terjadi di antara mereka. Rasa tabu itu didasari oleh norma agama yang tidak boleh menyebarkan kejelekan dan dianjurkan untuk menutupi cacat sesama saudara.

\section{Silaturrahmi, Bahsul Masa'il serta Tabayyun sebagai proses pencegahan Konflik}

Silaturrahmi sebagai proses pencegahan Konflik disebabkan oleh kesalahpahaman. Hal tersebut lebih mudah teratasi oleh silaturrahmi sebab dalam momen silaturrahmi terjadi relasi yang saling terbuka, upaya peringatan dini (erly warning) dengan sendirinya dapat berjalan sekaligus ada unsur reaksi cepat (rapid responses) bila terjadi konflik di antara mereka. Dalam momen silaturrahmi tidak jarang seorang Tgk yang tadinya saling mencerca dapat bertemu dan bertegur sapa. Dalam konflik yang bersifat internal, silaturrahmi dipandang efektif sebagai alat di dunia pesantren. Konflik internal yang umum terjadi adalah konflik keluarga. Demikian juga konflik antar pesantren, santri dapat diselesaikan dengan model silaturrahmi Silaturrahmi juga efektif sebagai media resolusi dengan 
dunia luar pesantren. Pesantren yang sedang berkonflik dengan partai tertentu dapat menjadi reda ketika pesantren tersebut mau menerima kunjungan tokoh partai politik atau pejabat pemerintah yang sedang berseteru dengannya. Sebagai tahapan pencegahan, silaturrahmi merupakan bentuk komunikasi yang di dalamnya terdapat unsur: 1). Komunikasi yakni dua pihak atau lebih; 2). Media yang dijadikan alat komunikasi, dalam dunia pesantren bisa berupa even keagamaan atau saling mengunjungi; 3). Pesan atau isi komunikasi. Model silaturrahmi dijadikan model pencegahan. Pencegahan merupakan bentuk pendekatan yang harus dipadukan dengan pendekatan lainnya dengan secara simultan agar penyelesaian konflik dapat terlaksana. Tiga pendekatan yang dimaksud seperti dijelaskan Hugh Miall dalam bukunya Contempory Conflict Resolustion: perdamaian (peace keeping), mendorong transisi dan transformasi konflik dengan upaya membentuk perdamaian (peace making) dan mendorong rekonsiliasi dengan membangun perdamaian (peace building) (Lambang Trijono, 2001).

Bahsul Masa'il (problem solving dialogue) di dalam konflik pesantren merupakan aspek penekanan sekaligus penyekat konflik. Dalam Bahsul Masa'il terjadi proses dialog untuk menyelesaikan persoalan. Konflik yang muncul disekat dalam ruang lingkup yang sempit agar subtansi penekanan dan penyekatan konflik melalui Bahsul Masa'il (problem solving dialogue) diadopsi dari ayat Alqur'an. tentang musyawarah (Q.S; Asy Syuura (42) ayat 38), Ali Imran (3) Ayat 159), mereka meyakini segala persoalan daat di atasi dengan jalan musyawarah. Kesemua itu dijabarkan dengan tahapan 1). Bila ada persoalan adakan dialog; 2). Dialog mengedepankan sikap santun dan toleransi; 3). Mau memaafkan terutama dari pihak yang dirugikan agar proses rekonsiliasi bisa berjalan lancer.

Dalam istilah pesantren, tabayun berarti klarifikasi atas suatu persoalan. Unsur yang terdapat dalam tabayun adalah : 1). Menghadirkan pihak yang berkonflik; 2). Mediator yang diterima oleh masing-masing pihak yang berkonflik; 3). Masing-masing pihak yang berkonflik menjelaskan persoalan; 4). Pihak mediator menawarkan solusi penyelesaian dan 5). Persetujuan bersama bentuk penyelesaian. Selaras dengan yang tersebut di atas, pengelolaan konflik di dunia pesantren dilakukan dengan landasan normatif agama yang difokuskan dalam bentuk kaidah fiqih; 1 . Kemadhorotan dapat dihilangkan; 2) Bila ada dua kemadhorotan, maka, diambil salah satunya yang lebih ringan; 3). Tidak boleh membuat kemadhorotan; 4). Apabila tidak mendapatkan semua, maka, jangan ditinggal semua. Dan 5). Mengkompromikan dua persoalan samasama baik. Kaidah-kaidah tersebut di atas menjadi landasan dalam mengelola konflik. Adapun, bentuk teknis yang terdapat melalui tabayun (klarifikasi) tidak lain adalah mengandung ajaran agar tidak mengeksploitasi konflik. Berpijak dari hal itu, maka, Tgk cenderung tidak memperpanjang masalah namun tetap mengakui apabila terjadi kesalahan pada masing-masing personal.

\section{Simpulan}

Dari berbagai konflik tersembuyi yang terjadi pesantren, sering kali bermula ketika sang Tgk yang berposisi sebagai pendiri sekaligus pemilik pesantren tersebut meninggal dunia. Atau hal yang sama juga terjadi ketika Tgk pesantren, pendiri atau yang melanjutkan, para ustadz, pengasuh, atau juga para keluarga ikut melibatkan diri pada urusan di luar pesantren, kenegaraan, politik dan lain-lainnya. Oleh sebab itu, upaya 
meredam resolusi konflik pesantren seringkali ditempuh dengan media perkawinan antar pesantren, istighotsah, haul dan acara akhirussanah. Dari berbagai acara rutinitas yang dilakukan oleh pesantren, maka, dapat dipastikan para individu yang sedang berkonflik akan mendatangi acara tersebut, sehingga sangat dimungkinkan menjadi ajang untuk memulai islah di antara mereka yang sedang bersengketa atau berkonflik. Secara tegas dapat dikatakan, tahapan resolusi konflik dilakukan melalui jalan silaturrahmi sebagai proses pencegahan konflik, bahtsul matsa'il sebagai proses penekanan dan peyekatan konflik, tabayun sebagai proses pengaturan dan pengelolaan konflik serta islah sebagai proses akhir penyelesaian konflik.

\section{Referensi}

Fealy, Greg dan Greg Barton (ed). 1997.

Tradisionalisme Radikal

Persinggungan Nabdatul Ulama

Negara. Yogyakarta: LkiS.

Keller, Suzane. 1995. Penguasa dan

Kelompok Elit. Jakarta: Radjawali

Press.

Majid, Nurcholis. 2009. Bilik-Bilik

Pesantren. Jakarta: Paramadina

Dian Rakyat. , 2009b. Merumuskan

Kembali Tujuan Pendidikan

Pesantren. Jakarta: Paramadina

Dian Rakyat.

Syarifudin, Hamdan Farchan. 2004. Titik

Tengkear Pesantren. Yogyakarta:

Pilar Media.

Trijono, Lambang. 2001. Keluar dari

kemelut Maluku. Yogyakarta:

Pustaka Pelajar.

Turmudi, Endang. 2001. Perselingkuban

Kyai dan Kekuasaan. Jakarta:

LP3ES.
Suryabrata. Sumardi. 2008. Metodologi Penelitian. Jakarta : Raja Grafindo Persada. 